\title{
Healthcare utilisation: a mixed- method study among tea garden workers in Indian context
}

\author{
Sonalee Rajput, Sibasis Hense and K.R. Thankappan \\ Department of Public Health and Community Medicine, Central University of Kerala, \\ Kasaragod, India
}

\begin{abstract}
Purpose - The study examined the utilisation patterns of healthcare services among tea garden workers and analysed the factors influencing utilisation in an Indian context.

Design/methodology/approach - The authors employed a mixed-method approach and an explanatory sequential design for the study. A survey was conducted in the beginning followed by in-depth interviews in a north-eastern state of India (Assam). Andersen health behaviour model was used to explore the factors influencing healthcare utilisation. The sample size for the survey and in-depth interviews were 300 and 19, respectively, recruited employing multistage random and purposive sampling techniques.

Findings - Out of 300 workers surveyed, $169(56.3 \%)$ were females, $257(85.7 \%)$ were married, $77(25.7 \%)$ were illiterates and $229(76.3 \%)$ had monthly household income less than 100 US\$. The survey also found that $47.3 \%$ and $15.3 \%$ had non-communicable and communicable disease respectively. Most of the workers $(67.3 \%)$ utilised government facilities, and close to one third $(28.7 \%)$ utilised tea garden hospitals. About $63.3 \%$ had health insurance, but a majority $(78.9 \%)$ did not use it previously. The analyses of interviews explored the need, enabling, predisposing factors under three important themes influencing utilisation of healthcare services among the workers.

Practical implications - The study generates evidence to strengthen the Indian Plantation Labour Act, 1951 for tea garden worker's welfare protection and warrants transition from colonial-era policies to contemporary industry realities in order to improve their living, employment, nutritional and health conditions.

Originality/value - The research adds to the existing literature on overall healthcare services utilisation (including coverage and utilisation of health insurance) among blue collar workers who usually lack access to healthcare facilities and explores important factors that determine utilisation in the Indian context.
\end{abstract}

Keywords Healthcare services utilisation, Anderson model, Tea gardens workers, India

Paper type Research paper

\section{Introduction}

Access to healthcare is one of the essential components of healthcare services utilisation and for ensuring universal health coverage [1]. The global burden of disease (GBD) study has estimated the healthcare access and quality index (HAQ) for 195 countries [1]. As per this index, Iceland had the highest score (97.1 out of 100) and the Central African Republic had the lowest score 18.6 [1]. India scored 41 and ranked 145 among 195 countries. In India, Assam, a north-eastern state had the lowest score (34.0), indicating a higher level of disparity among the Indian states [1].

(c) Sonalee Rajput, Sibasis Hense and K.R. Thankappan. Published in Journal of Health Research. Published by Emerald Publishing Limited. This article is published under the Creative Commons Attribution (CCBY 4.0) licence. Anyone may reproduce, distribute, translate and create derivative works of this article (for both commercial and non-commercial purposes), subject to full attribution to the original publication and authors. The full terms of this licence may be seen at http://creativecommons. org/licences/by/4.0/legalcode

The authors thank all the study participants involved in this study. The author(s) would also like to acknowledge the important contribution of Dr Vellikkeel Raghavan in proofreading the manuscript.

Funding: No funding received to undertake this study.

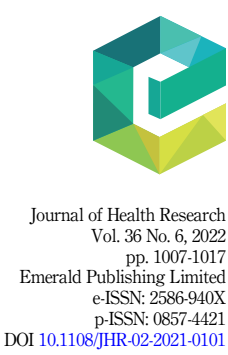


JHR

36,6

The state of Assam is popularly known for tea plantation, contributing about one-fifth to the state GDP [2]. Many casual and full-time workers across Indian states depend upon Assam's tea estates for their livelihood [3]. But, due to multiple reasons the health status of these workers is reported to be much lower than the state average [4]. These workers often lack access to basic amenities including schools, latrines, safe drinking water, healthcare and nutrition [4]. Due to poor access, they experience higher maternal mortality rate (404 per 100,000 live births), higher risk of pregnancy-related complications, hypertension (60\%), poor nutritional status, low birth weight babies ( $43 \%$ ) and higher prevalence of Tuberculosis (TB) (30-40\%) compared to the general population in the state [4-6].

According to the Indian Plantation Labour Act, 1951, the tea garden authorities are mandated to provide the basic amenities of healthcare, education, drinking water, housing, child care facilities, maternal care and accident cover to all their workers in addition to minimum wage and maximum duty hour's provision [7]. However, there exist significant gaps across the state in implementation of this Act, primarily with respect to provision for basic amenities [3]. There are also evidences of mortalities attributed to tuberculosis, high blood pressure, lack of access to treatment and lower utilisation of healthcare services among the tea garden workers and their family members [4]. These evidences suggest discrepancies in healthcare access and utilisation by the tea garden workers in the state of Assam.

While a majority of research on the tea garden workers in India mainly focused on their health/nutritional status [4, 8] contraceptive practice [9], living, education, economic, employment status [10] and utilisation of sanitation facilities [11], studies specifically on health services utilisation are scant except for a few studies on maternal and neonatal health services utilisation and social determinants on health among the tea garden workers [12] in the region.

The Andersen health behaviour model [13] is designed to examine the determinants of health services utilisation and measures inequities in health service access amongst ethnic minorities and rural and remote populations. It identifies predisposing, enabling and need factors as determinants of healthcare service use. According to this model health services use can be predicted or explained by population characteristics, including individual's predispositions to use services, resources that enable or impede use and their need for care. Predisposing factors reflect the individual's propensity to use health services which exist prior to the illness such as demographics, social structure and health beliefs, etc. Enabling factors are the resources that may facilitate access to services. It is a condition that may be changed by an individual and social efforts such as health insurance, free healthcare services, knowledge about own health status etc. and the need factors represent potential needs of health service use, such as self-perceived health, chronic conditions and restricted activity. Given this background, we examined the utilisation pattern of healthcare services and factors influencing utilisation by the tea garden workers in one of the backward districts of Assam.

\section{Methodology}

\subsection{Study design}

We used a sequential mixed-methods approach [14], wherein a quantitative phase (survey) was conducted in the beginning followed by the qualitative phase (in-depth interviews).This design was used because the quantitative data helped examine the utilisation pattern of healthcare services among the workers, assisted in identifying participants for follow-up interviews in the qualitative phase that explored the determining factors influencing utilisation in greater detail.

\subsection{Study settings}

This study was conducted in Golaghat district of Assam across three tea garden estates (TGEs): Radhabari, Bokakhat and Borjuri. The district was selected considering lower 
composite health index (below 50\%) and a high priority district in the state of Assam and in the country [15]. Moreover, there are a large number of tea estates (74 in numbers) in this district and it has the highest maternal mortality rate (404 per 100,000 live births) [16].

\subsection{Inclusion and exclusion criteria}

The study was conducted among the tea garden workers, between the age group of 18-60 years, who in the past six months (i.e. between June and November 2019) had utilised any type of healthcare services. The participants for in-depth interviews were recruited from the survey participants who gave consent to be interviewed.

\subsection{Sampling}

Sampling was done for both quantitative (survey) and qualitative (in-depth interviews) phases of the study. The sample size for the survey was calculated using the formula, $S=Z 2 P^{*}(1-P) / \mathrm{ME}^{2}$, where " $Z$ ' is the critical ratio for $95 \%$ confidence interval (1.96), and " $P$ " is the anticipated proportion of population utilisation rate for in-patient and out-patient services among general population of Assam i.e. $50 \%$, "ME" is the margin of error which was taken as $6 \%$. Applying a non-response rate of $10 \%$, the sample size was calculated at 293.26 , which was rounded off to 300 . The participants of this study were recruited employing multistage random sampling.

A sub-division (Bokakhat sub-division) of the district was selected randomly using the lottery method from 3 sub-divisions in Golaghat district. The Bokakhat sub-division had 11 TGE of which three TGEs i.e. Bokakhat T.E, Radhabri T.E and Borjuri T.E. were randomly selected using a lottery method. Each of the above tea gardens had. 3,115, 618 and 254 workers (including seasonal workers) respectively. A total of 100 tea garden workers from each of the three TGE were recruited employing a random sampling technique from the list of tea garden workers obtained from the tea garden estate administration. If the selected worker did not utilise health services in the previous six months the next worker was selected from the list who utilised health services in the previous six months. In the qualitative phase, nineteen workers were recruited from the survey participants purposefully, who were local people, working in the surveyed TGEs since last one-year, utilised health services in the past six months and gave consent for the follow-up interviews in the qualitative phase.

\subsection{Data collection tools and techniques}

In the quantitative phase, an adapted questionnaire from LASI (Longitudinal Ageing Study in India) was used to collect data. Specifically, "heath insurance and services utilisation" section of the questionnaire was used in this study to meet the study objectives after ensuring the content and face validity. While the overall LASI tool is designed for individuals aged 45 years and above, this section of the tool was not dependent on any specific age groups; hence, it allowed the researchers to obtain data from the tea garden workers without any age restrictions [17]. In addition, the socio-demographic details of the tea garden workers their occupation and income details and health status were obtained. Socio-demographic details included age, sex, religion, marital status, education, living arrangement, type of family and number of family members. Occupation and income details of the workers included their monthly household income, nature of occupation and number of family members working in tea garden. Health status of the workers was assessed self-reported illnesses by asking if the respondent was suffering from any health ailments: communicable diseases, noncommunicable diseases and disabilities. The pattern of healthcare service utilisation was measured in terms of the type of healthcare facilities used; healthcare providers visited, health services availed and health insurance usage in the last six months. 
JHR

36,6

1010

In the qualitative phase, in-depth interview method was employed using a semi-structured interview guide. This interview guide was developed using Andersen and Newman framework [13] of healthcare services utilisation considering the need, predisposing and enabling factors. A translated interview guide in vernacular (Assamese) language was used to conduct the interviews among a selected group of the tea garden workers selected purposefully. Each interview lasted for about 40-60 minutes, were audio recorded, translated in English, transcribed verbatim in Microsoft-Word version-11 (coded deductively for descriptive and Invivo codes).

\subsection{Data analysis}

The analysis of survey data was done using SPSS version 22. Descriptive statistics was used to analyse the survey data. The descriptive statistics consisted of univariate analysis such as calculation of frequencies and percentage for categorical variables. The data analysis for in-depth interviews of the tea garden workers was done thematically using N-Vivo version 12 .

\subsection{Ethical considerations}

This study was conducted after obtaining approval from the Central University of Kerala, Kasaragod (India), Institutional Human Ethical Committee (CUK/IHEC/2019/054).

\section{Results}

\subsection{Quantitative results}

The survey data were analysed for 300 tea garden workers. The socio-demographic characteristics of the workers are given in (Table 1). Among the survey sample, more than half $(56.3 \%)$ were females. About one-fourth $(25.7 \%)$ were illiterate and a majority $(76.3 \%)$ of them have a household income of less than INR 6,500 a month (i.e. less than 100 USD).

Self-reported illnesses and disability among the workers are given in Table 2.

Most $(67.30 \%)$ of the workers utilised government facilities while only $4 \%$ utilised private facilities such as nursing homes or private clinics, and close to one third $(28.7 \%)$ of the workers utilised not-for-profit hospitals (i.e. tea garden hospitals). The preference of consulting allopathic physicians was high among the workers (77\%). Interestingly, more than half of the workers (51\%) also reported consulting folk/traditional healers (Figure 1).

The survey data also revealed that $70.7 \%$ of the workers utilised outpatient services while $29.3 \%$ utilised in-patient services. Of the total outpatient services utilised $212(70.7 \%), 23.6 \%$ was for laboratory services, $18.8 \%$ was for radiological investigations, $10.4 \%$ was for ANC and immunisation, and $47.2 \%$ was for other types of OPD services such as physician consultation (Figure 2). Of the total inpatient services utilised by the workers $88(29.3 \%)$, $14.7 \%$ had some surgical procedures, $22.3 \%$ had undergone laboratory investigations, $18 \%$ had radiological investigations, $4.5 \%$ had utilised emergency services and the remaining $40.5 \%$ were on medical management alone (Figure 2).

More than half of the workers $(63.3 \%)$ had health insurance and they were covered mainly under the Indian Government Health Insurance Scheme (99\%) i.e. Ayushman Bharat and Atal Amrit Abhiyan, while 16\% did not even know whether they were covered under any type of health insurance scheme. However, $150(78.9 \%)$ of them did not utilise the scheme during their last visit to the healthcare facility (Figure 3).

\subsection{Qualitative results}

The analysis of in-depth interviews explored the need, predisposing, enabling and other inhibiting factors influencing utilisation of healthcare services among the tea garden workers. The detailed outlay of the themes and sub-themes is given in Figure 4. 


\begin{tabular}{|c|c|c|c|c|}
\hline Variables & Categories & Frequency & $\%$ & itil \\
\hline \multirow[t]{2}{*}{ Sex } & Male & 131 & 43.7 & tea-garde \\
\hline & Females & 169 & 56.3 & lea-gar ue \\
\hline \multirow[t]{2}{*}{ Age (years) } & $\leq 39$ & 210 & 70 & workers \\
\hline & $\geq 40$ & 90 & 30 & \\
\hline \multirow[t]{2}{*}{ Religion } & Hindu & 294 & 98 & \\
\hline & Christian & 6 & 2 & 101 \\
\hline \multirow[t]{3}{*}{ Marital status } & Unmarried & 24 & 8 & 10 \\
\hline & Married & 257 & 85.7 & \\
\hline & Others (Widowed, divorce and separated) & 19 & 6.3 & \\
\hline \multirow[t]{3}{*}{ Education } & No schooling & 77 & 25.7 & \\
\hline & $<5$ years of schooling & 126 & 42 & \\
\hline & $\geq 5$ years of schooling & 97 & 32.3 & \\
\hline \multirow[t]{2}{*}{ Number of family members } & $<6$ & 202 & 67.3 & \\
\hline & $\geq 6$ & 98 & 32.7 & \\
\hline \multirow[t]{2}{*}{ Number of family members working in tea garden } & 1 & 61 & 20.3 & \\
\hline & $>1$ & 239 & 79.7 & \\
\hline \multirow[t]{2}{*}{ Family members unemployed (18 years and above) } & Yes & 106 & 35.3 & Table 1. \\
\hline & No & 194 & 64.7 & Socio-demographic, \\
\hline \multirow[t]{2}{*}{ Monthly household income in INR } & $<6500$ & 229 & 76.3 & income and occupation \\
\hline & $\geq 6500$ & 71 & 23.7 & details of the tea \\
\hline \multirow[t]{2}{*}{ Nature of occupation } & Permanent & 203 & 67.7 & garden \\
\hline & Causal & 97 & 32.3 & workers $(n=300)$ \\
\hline
\end{tabular}

\begin{tabular}{|c|c|c|c|c|}
\hline Variables & Categories & Frequency & $\%$ & \\
\hline \multirow[t]{3}{*}{ Self-reported health ailments $(n=300)$} & No health ailments & 111 & 37.0 & \\
\hline & Communicable disease & 47 & 15.7 & \\
\hline & Non-communicable disease & 142 & 47.3 & \\
\hline \multirow{7}{*}{$\begin{array}{l}\text { Type of non-communicable diseases - Self- } \\
\text { reported }(n=142)\end{array}$} & Diabetes mellitus & 11 & 7.8 & \\
\hline & Hypertension & 51 & 35.9 & \\
\hline & Heart disease & 12 & 8.5 & \\
\hline & Chronic lung disease & 8 & 5.6 & \\
\hline & Cancer & 8 & 5.6 & \\
\hline & Musculoskeletal disorder & 25 & 17.6 & \\
\hline & $\begin{array}{l}\text { Others (Gastrointestinal and } \\
\text { neurological disorders) }\end{array}$ & 27 & 19.0 & $\begin{array}{r}\text { Table } 2 . \\
\text { Self-reported illnesses }\end{array}$ \\
\hline \multirow[t]{2}{*}{ Any known disability- self-reported $(n=300)$} & Yes & 31 & 10.3 & and disability among \\
\hline & No & 269 & 89.7 & the tea garden workers \\
\hline
\end{tabular}

3.2.1 Severity of illness and a quick-fix remedy. The workers reported that their decision to visit tea garden hospital or any nearby health centre depends on the severity of their symptoms and the pain they experienced due to their illness. The need to visit a health centre and utilise services was better captured in one of the interviews with a female worker. She mentioned that:

....... Whenever I fall sick, I first opt for home remedies. Only If I suffer severely, I prefer to consult a doctor (Participant-1)

The workers viewed that the uptake of healthcare services depend on the medical treatment that offered speedy recovery. Therefore, they often explore alternate options for a quick-fix cure or suitable treatment to their health conditions/problems. In this regard, one male worker said: 
JHR
36,6

\section{2}

\section{Figure 1.}

Utilisation of health services among the tea garden workers
Figure 2.

Utilisation of outpatient and in-patient services among the tea garden workers
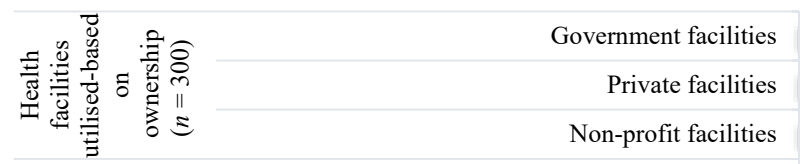

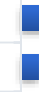

Non-profit facilities

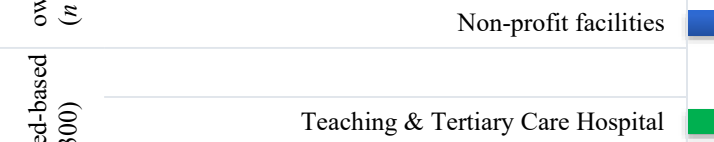

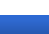

$28.70 \%$

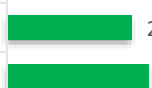

$28.70 \%$

District \& Sub-divisional Hospital

$32.60 \%$

Primary Health Centre

$4.00 \%$

Sub-centre $2.00 \%$

Tea Garden Hospital

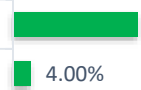

$28.70 \%$
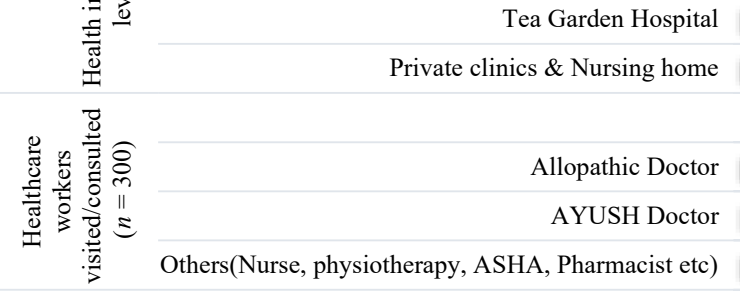

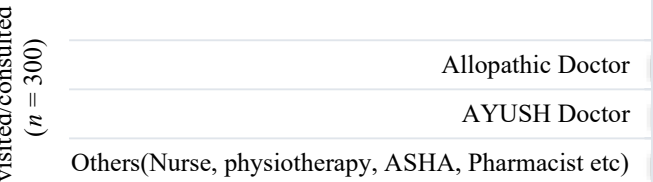

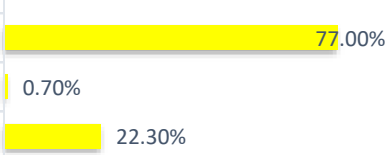

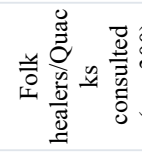

\&
II
$\Xi$

Yes

$51.00 \%$

No

$49.00 \%$

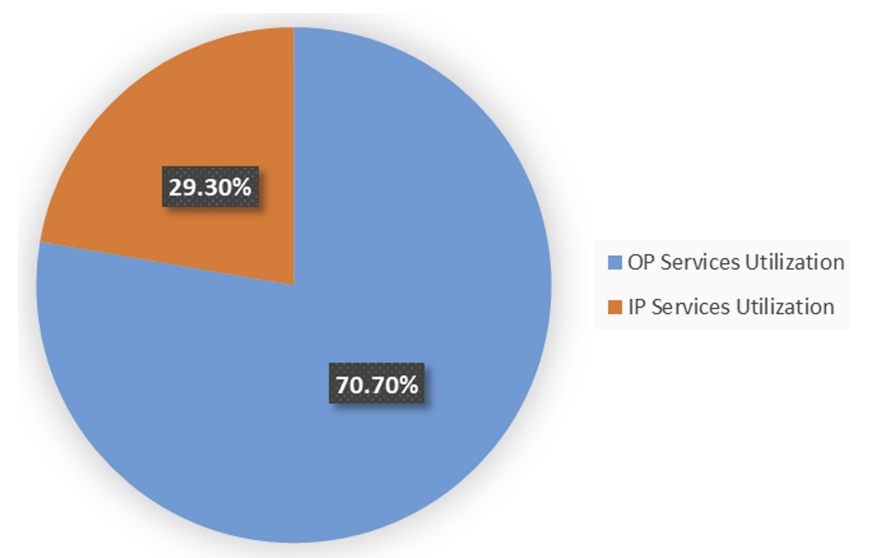

When you're in pain, you have to look at different places to find out how you can get better. As a labourer I can't wait for a long time for recovery. So, I want a speedy recovery that is the reason I went to Golaghat district hospital (Participant-5).

3.2.2 Accessibility and affordability of healthcare services. The workers opined that health services that are accessible and affordable are more likely to be utilised. In the interviews, almost all the participants found to sought diagnoses and initial treatment from tea garden hospitals because it was accessible, offered free medicines and met the immediate healthcare need of the workers. 


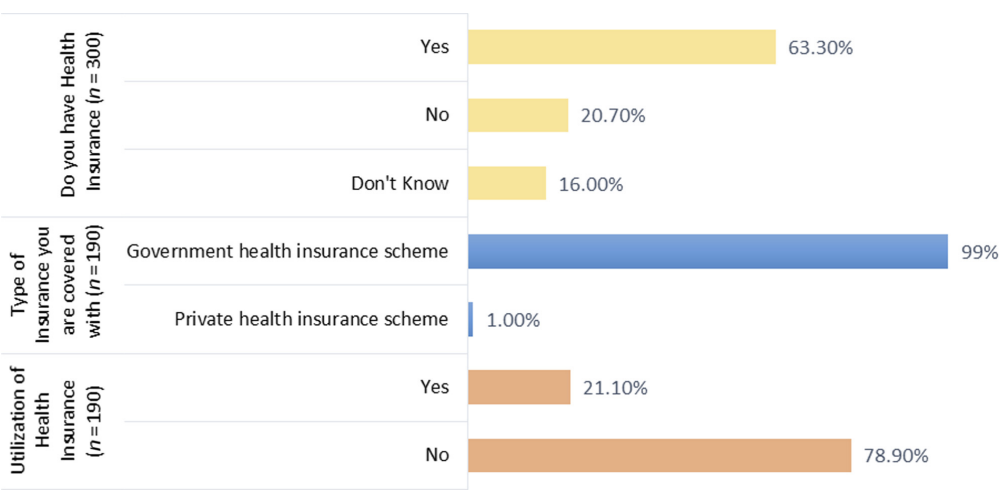

\section{Healthcare utilisation and tea-garden workers}

1013

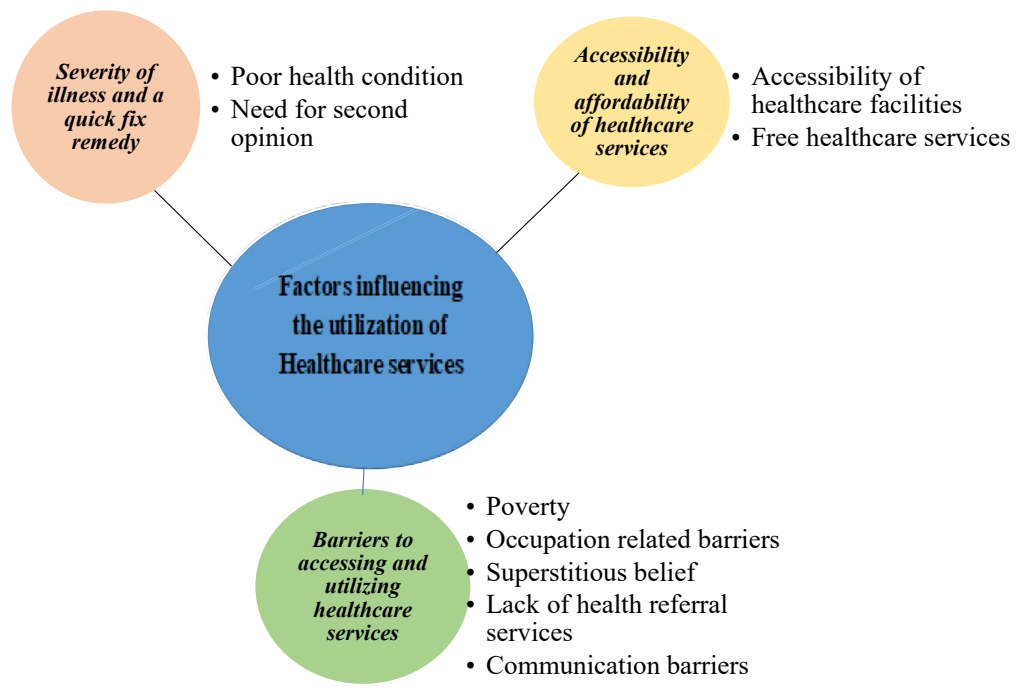

Figure 4. Factors influencing the utilisation of healthcare services among the tea garden workers

I visit tea garden hospital because it is nearby and their services are free. I think only tea garden hospital is more suitable to the word accessible and affordable but to what extent the services are available in our tea garden is questionable. If you are ill, definitely you will go to the nearest hospital. (Participant-4).

3.2.3 Barriers to accessing and utilising healthcare services. Issues like poverty, employment challenges, lack of awareness about health, poor referral services, superstitious belief and communication gap between patient and healthcare providers were found to be the leading predisposing factors impeding utilisation of healthcare services. Even, utilisation of healthcare services was not seen as a priority due to poverty. It was best illustrated in the following statement:

I don't have much money in my bank account so I cannot go elsewhere for treatment at our own cost. I would prefer only tea garden hospital for seeking treatment rather than going to other big hospital (participant no-1). 
JHR

36,6

1014

The workers also quoted busy work schedule, intermittent or seasonal employment, tremendous physical labour and longer working hours as important occupational barriers in utilisation of healthcare services in the region. The interviews also noted female workers were missing out their health check-up due to heavy work load in tea gardens and household chores. In this regard, one worker said:

Iam a woman, after 8 hours of hard work I need to take care of my children, and household work. It is very difficult to arrange time for my health (Participant-2).

The lack of awareness about health and superstitious belief were viewed as barriers among the workers. Almost all the workers interviewed stated that at some point in time they visited traditional healer and priest during the illness period. They also felt that taking such remedies would result in speedy recovery at a lower cost. A male tea garden worker suffering from jaundice shared that:

First, I prefer to go to tea garden hospital but if I don't get relief I go to traditional healers and get the remedies and Yes, the superstitious power works for me. (Participant-5).

The interviews noted poor referral services in the tea garden areas have affected utilisation of healthcare services. The workers complained of unavailability of infrastructure for patient referral and transportation. This is captured in an interview with one of the workers

Our tea garden management authority gives referral services to the permanent workers only. The full-time regular worker gets bonus money, reimbursement money, referral service etc. But we are not getting all these facilities. (Participant-8).

The workers interviewed shared that regular full-time workers get referral services and not the seasonal workers. Therefore, it can be argued that the tea garden administration has neglected or failed to provide inclusive referral services to all workers; even though it is an important area it has not been addressed.

\section{Discussions}

Our study noted interesting utilisation patterns of healthcare services among the tea garden workers. In our study $47.3 \%$ and $15.3 \%$ of the tea garden workers reported to have noncommunicable and communicable diseases respectively, who may require regular visits to a healthcare facility. Similar disease pattern (such as hypertension, stroke, anaemia, tuberculosis, respiratory infections) are well documented from this region [8]. We also noted that a majority of the workers (76.3\%) had less than INR 6500 (less than USD 100) of household income a month which seems to have not changed significantly in the last decade.

A sizeable proportion (32.3\%) of the workers was employed casually who are generally denied of healthcare services by the TGEs administration through their tea garden hospitals. Most of the workers surveyed had utilised government hospitals $(67.3 \%)$ previously and the remaining, either utilised a private not-for-profit tea garden hospital $(28.7 \%)$ or a private for-profit facility like nursing homes/clinics (4\%). These findings are in concurrence with earlier literature that suggested blue collar and casual workers tend to use public services while the wealthier tend to consult private health services [18]. This also indicates greater utilisation of government healthcare facilities compared to private facilities by the workers, primarily due to the higher cost of medical treatment in the private sector and poor household income of the workers.

The idea of affordability and accessibility also emerged in the interviews as these elements were found to be influencing the health services utilisation of the workers. Specifically, we observed that healthcare services which are affordable and accessible are more likely to be utilised by the workers. In contrast, it is also interesting to note an increasing trend in the utilisation of private health facilities across Indian states [19] due to low investment in the 
public health sector and a growing middle-class population increasingly demanding better quality of healthcare services [19]. However, the economically weaker section (such as the tea garden workers) still depends on government healthcare services in the country [18]. Therefore, this study calls attention to policy makers towards greater investment in the public health sector to make healthcare more affordable and accessible, especially for the weaker economic section of the society including the tea garden workers whose earning has been dismally low.

According to the Plantations Labour Act, 1951 [7], the tea garden employers are mandated to provide medical facilities, clean drinking water, latrines and urinals to all cadres of workers in plantation areas. Tea garden workers are highly dependent on their employers, as there is limited access to education and economic opportunities outside tea plantations areas in the region. Our interviews identify leniency in implementation of the Act in the tea garden areas surveyed. Our interview participants (especially the causal/part-time workers) reveal that they lack access to basic medical facilities, referral facilities and are living with compromised amenities and poor working conditions. Similar issues are also reported in previous literature including poor living and working conditions [12] non-availability of doctors and medicines in tea garden hospitals [12] as well as sanitation and housing facilities [11].

In another interesting finding we noted that despite the Indian Government's effort to popularise Ayurveda Yoga Unani Siddha Homeopathy (AYUSH) system of medicine, tea garden workers are still inclined towards the modern system of medicine. This was similar to the national level data (by the National Sample Survey Office- NSSO) that found a higher tendency $(90 \%)$ towards utilisation of allopathy treatment in India. In both rural and urban settings, only $5-7 \%$ use AYUSH systems of medicine [20]. Similar observations were recorded in our study where a majority of the workers were found to seek treatment from allopathic doctors $(77 \%)$ vis 'a vis AYUSH doctors $(0.70 \%)$. This indicates the preference of tea garden workers towards allopathic treatment. One of the possible reasons why a majority of the tea garden workers visited allopathy physicians emerged in our qualitative findings where the workers prefer to get quick-fix remedy for their health problem to resume work/earning. Additionally, nearly $51 \%$ of the workers had visited quacks/folk/traditional healers for treatment. Illiteracy, poor income and less treatment cost are the few factors responsible for seeking treatment from quacks/folk healers emerged in the interviews with the workers.

Our study also found that $63.3 \%$ of the workers had health insurance, of which a majority $(78.9 \%)$ did not use previously. Surprising, $16 \%$ did not even know whether they were covered under any type of health insurance schemes such as Ayushman Bharat Abhiyan (Govt. of India) or Atal Amrit Abhiyan, Govt. of Assam, which they are entitled for due to their economic status. These findings contradicted existing literature that demonstrated possession of health insurance scheme was positively associated with higher utilisation of health facilities, particularly among below poverty level populations [21]. Lack of education and awareness among the tea garden workers could be the possible reasons for ignorance about different government health funding schemes in the region [10]. Therefore, more actionbased research must be undertaken to raise awareness about various government health insurance policies and their utilisation. For this purpose, proper arrangements of sensitisation camps by the tea garden estate administration in collaboration with the district health administration needs to be conducted so that the workers are aware of the available health schemes offered by both the state and central governments.

In addition to the patterns of healthcare services utilisation, our study also observed a multitude of barriers inhibiting healthcare services utilisation among the tea garden workers in the region. The barriers cited by participants included lack of referral services, unavailability of doctors and medicines in tea garden hospitals, difficulties in patientphysician communication and poor support from the employers. These barriers did exist in
Healthcare utilisation and tea-garden workers

1015 
JHR

36,6

the literature for decades [1-3] and have been unchanging all the while. Therefore, we argue that studies may be conducted among healthcare providers, tea garden authorities and tea garden hospitals to better understand their perspectives towards providing welfare assistance including healthcare access to overcome the healthcare utilisation barriers.

\section{Conclusion}

This study identifies the pattern of illness and health services utilisation including awareness and usage for health insurance among the tea garden workers in Assam. It also explored the associated facilitating factors as well as barriers responsible for utilisation of healthcare services. The study also generates evidence to strengthen the Indian Plantation Labour Act, 1951 with respect to daily living and working conditions, uniformity of minimum wages and provision for better healthcare facilities. These can be attained through well-resourced tea garden hospitals, convergence of health and other welfare programmes and intersectoral coordination among state, central, health authorities and tea boards. Our findings also warrant policy makers for a transition from colonial-era policies and shift towards contemporary industry realities for improving the living, working and health conditions of the tea garden workers in the Indian context.

\section{Limitations}

Like all surveys, our study relied on self-reported data, so recall bias may limit the reliability of findings. The views of key informants in respect to health services utilisation were not captured in this study due to time and permission constraint. Lastly, the data collected were drawn only from three tea gardens of Golaghat district. Hence, the results may have limited generalisability. Future research needs to improve upon these limitations.

Conflict of Interest: None

\section{References}

1. Fullman N, Yearwood J, Abay SM, Abbafati C, Abd-Allah F, Abdela J, et al. Measuring performance on the healthcare access and quality index for 195 countries and territories and selected subnational locations: a systematic analysis from the global burden of disease study 2016. Lancet. 2018; 391(10136): 2236-71. doi: 10.1016/s0140-6736(18)30994-2.

2. Kausar A, Giri S, Roy P, Giri A. Changes in buccal micronucleus cytome parameters associated with smokeless tobacco and pesticide exposure among female tea garden workers of Assam, India. Int J Hyg Environ Health. 2014; 217(2-3): 169-75. doi: 10.1016/j.ijheh.2013.04.007.

3. Baishya D. History of tea industry and status of tea garden workers of Assam. Int J Appl Res. 2016; 2(9): 552-6.

4. Sahoo D, Konwar K, Sahoo BK. Health condition and health awareness among the tea garden laborers: a case study of a tea garden in Tinsukia district of Assam. IUP J Agri Econ. 2010; 7(4): 50-72.

5. Borah PK, Kalita HC, Paine SK, Khaund P, Bhattacharjee C, Hazarika D, et al. An information, education and communication module to reduce dietary salt intake and blood pressure among tea garden workers of Assam. Indian Heart J. 2018; 70(2): 252-8. doi: 10.1016/j.ihj.2017.08.008.

6. Phukan RK, Mahanta J. A study of neonatal deaths in the tea gardens of Dibrugarh district of upper Assam. J Indian Med Assoc. 1998; 96(11): 333-4.

7. Tea Board India. Plantations labour Act, 1951. [cited 2019 Aug 13]. Available at: http://www. teaboard.gov.in/pdf/policy/plantations\%20labour\%20act_amended.pdf.

8. Medhi GK, Hazarika NC, Shah B, Mahanta J. Study of health problems and nutritional status of tea garden population of Assam. Indian J Med Sci. 2006; 60(12): 496-505. doi: 10.4103/0019-5359.28979. 
9. Saha SK, Bag T, De Aloke K, Basak S, Chhetri A, Banerjee J. Contraceptive practice of the tribal women in tea garden area of North Bengal. J Indian Med Assoc. 2007; 105(8): 440-448.

10. Bosumatari D, Goyari P. Educational status of tea plantation women workers in Assam: an empirical analysis. Asian J Multidisci Stu. 2013; 1(3): 17-26.

11. Bora PJ, Das BR, Das N. Availability and utilization of sanitation facilities amongst the tea garden population of Jorhat district, Assam. Int J Community Med Pub Health. 2018; 5(6): 2506-11. doi: 10. 18203/2394-6040.ijcmph20182186.

12. Bhattacherjee S, Datta S, Saha JB, Chakraborty M. Maternal health care services utilization in tea gardens of Darjeeling, India. Journal of Basic and Clinical Reproductive Sciences. 2013; 2(2): 77-84.

13. Aday LA, Andersen R. A framework for the study of access to medical care. Health Serv Res. 1974; 9(3): 208-20.

14. Creswell JW, Plano Clark VL, Gutmann ML, Hanson WE. Advanced mixed methods research designs. In: Tashakkori, A, Teddlie, C, (Eds). Handbook of mixed methods in social and behavioral research. Thousand Oaks, California, CA: Sage; 2003: 209-40.

15. India, Ministry of Health and Family Welfare [MoHFW], National Rural Health Mission [NRHM]. Guidance note for implementation of RMNCH+A interventions in high priority districts. New Delhi: NRHM; 2013.

16. India, Office of the Registrar General and Census Commissioner, Vital Statistics Division. Annual health survey 2012-13 fact sheet: Assam. New Delhi: Vital Statistics Division; 2014.

17. International Institute of Population Sciences [IIPS]. Longitudinal ageing study in India (LASI). [cited 2019 Aug 13]. Available at: http://14.143.90.243/iips/content/lasi-goals.

18. Levesque JF, Haddad S, Narayana D, Fournier P. Outpatient care utilization in urban Kerala, India. Health Policy Plan. 2006; 21(4): 289-301. doi: 10.1093/heapol/czl013.

19. Singh PK, Rai RK, Alagarajan M, Singh L. Determinants of maternity care services utilization among married adolescents in rural India. PloS One. 2012; 7(2): e31666. doi: 10.1371/journal.pone. 0031666.

20. Rudra S, Kalra A, Kumar A, Joe W. Utilization of alternative systems of medicine as health care services in India: evidence on AYUSH care from NSS 2014. PloS One. 2017; 12(5): e0176916. doi: 10. 1371/journal.pone.0176916.

21. Sreeramareddy CT, Sathyanarayana TN, Kumar HN. Utilization of health care services for childhood morbidity and associated factors in India: a national cross-sectional household survey. PloS One. 2012; 7(12): e51904. doi: 10.1371/journal.pone.0051904.

\section{Corresponding author}

Sibasis Hense can be contacted at: sibahense@gmail.com

For instructions on how to order reprints of this article, please visit our website:

www.emeraldgrouppublishing.com/licensing/reprints.htm

Or contact us for further details: permissions@emeraldinsight.com 